\title{
Open Source Interpretation
}

\author{
Eli Greenbaum ${ }^{a}$
}

(a) Partner, Yigal Arnon \& Co.

DOI: $10.5033 /$ jolts.v12i1.143

\begin{abstract}
This Article offers an alternative to the standard assumptions concerning the interpretation of Free and Open Source Software licenses - that such licenses should be interpreted as boilerplate agreements applied by the licensing parties without having negotiation regarding the language of the license. The Article considers some of the consequences of this approach to license interpretation.
\end{abstract}

\section{Keywords \\ Law; information technology; Free and Open Source Software}

Should ordinary principles of contract interpretation apply to Free and Open Source Software ("FOSS") licenses? Courts ${ }^{1}$ and commentators ${ }^{2}$ have generally assumed that Free and Open Source Software should be interpreted as classical contracts - and, as such, should be construed to reflect the intentions of the parties to the licensing transaction. ${ }^{3}$ According to this approach, the interpretative guidance of license stewards and industry associations may have limited effect on the understanding of FOSS licenses, but such comments would have less significance that the intentions of the licensor and licensee themselves. ${ }^{4}$ Moreover, according to this approach, common cannons of contractual

1 To the extent United States courts have had the opportunity to interpret FOSS licenses, they have generally not explained their reasoning. See, e.g., Jacobsen v. Katzer, 535 F.3d 1373, 1381 (Fed. Cir. 2008) (interpreting the terms of the Artistic License, without explanation of the underlying interpretative principles). Some United States courts have had the opportunity to interpret Creative Commons licenses (which are not geared towards the licensing of software), and such courts have generally assumed that they can "property rely on traditional tools of contract interpretation." Drauglis v. Kappa Map Group, LLC, 128 F. Supp. 3d 46, 53 (D.D.C. 2015). See also Great Minds v. Office Depot, Inc., 945 F.3d 1106 ( $9^{\text {th }}$ Cir. 2019); Great Minds v. FedEx Office \& Print Servs., 886 F.3d 91 (2d Cir. 2018).

2 See Lawrence Rosen, Open Source Licensing Software Freedom and Intellectual Property Law 120 (2004); Heather MeEker, Open Source For Business 98 (2017) (stating that "there is no reason to think that the rules of interpretation" applicable to the GPL "would be different from those applied anywhere else in the law"); Lothar Determann, Dangerous Liaisons-Software Combinations as Derivative Works? Distribution, Installation, and Execution of Linked Programs under Copyright Law, Commercial Licenses, and the GPL, 21 BeRK. TеCH. L.J. 1421, 1491 (2006) (asserting that, in interpreting the GPL "courts would likely apply contract interpretation rules and try to determine the intent of the copyright owner who selected the GPL and the licensee who selected the program"). But see Van Lindberg, OSS and FRAND, Complementary Models for Innovation and Development, 20 Columb. SCIENCE \& TECH. L.R. 251 (2019) (since licenses are chosen and not negotiated, "some typical canons of license interpretation may not apply in the open source context").

3 Rosen, supra note 2 at 120 (asserting that "[u]nder the law, only the common understanding of a licensor and his licensees matters, as reflected in the written terms and conditions of the license agreement between them"); Lindberg, supra note 2, at 257 (using the Open Source Definition to "illuminate the 'meeting of the minds' between licensor and licensee to the extent it exists"). Jason B. Wacha, Taking the Case: Is the GPL Enforceable?, 21 Santa Clara High Tech. L.J. 451,487 (2004). (asserting that "even if the FSF's language is additive, in analyzing a contract, a U.S. court would look to the intent of the parties"); Determann, supra note 2, at 1491 (asserting that in a dispute about the GPL, "courts would likely apply contract interpretation rules and try to determine the intent of the copyright owner who selected the GPL and the licensee who selected the program").

4 Rosen at 120 (asserting that "it is legally unnecessary to know what the drafter of a license - usually just an attorney with no stake in the matter-meant to say"); LindBERG, supra note 2, at 257, n.18 (asserting that for the interpretation of open 
interpretation should equally apply to the understanding of FOSS licenses. ${ }^{5}$

This article outlines a potential alternative approach: that Free and Open Source Software are not employed in transactions in which parties negotiate a classic contractual "meeting of the minds". Rather, FOSS licenses are fixed, template documents, which parties choose and apply across a range of transactions without negotiating their language or meaning. Indeed, as discussed below, FOSS communities find value in this template nature of FOSS licenses. As such, according to this alternative approach, the interpretation of FOSS licenses should not be characterized by a search for the intentions of the contracting parties, but rather by an inquiry into the meaning attached to these documents by the broader FOSS community and the expectations of that community regarding the application and effects of the license document. In this respect, FOSS licensing shares similarities with other transactions implemented by template language, and courts may decide that FOSS licenses should be interpreted using the specific principles applicable to this category of transactions. ${ }^{6}$

More specifically, this article examines a line of cases in which such "template" interpretive principles have been applied to the boilerplate language of financial contracts. FOSS licenses and financial contracts obviously differ significantly in their structure and goals, and the communities that employ these documents themselves differ in their organization and practices. Nonetheless, this article proposes that the interpretive cannons applicable to financial boilerplate can be usefully applied to understand the meaning of FOSS licenses. This article also outlines some of the consequences of applying this mode of interpretive analysis to FOSS licenses. To be clear, the intention of this article is not to assert that courts will use such "boilerplate" principles to interpret FOSS licenses to the exclusion of other interpretive methodologies. Rather, the intention is to propose that these principles can be usefully employed in understanding and interpreting the language and usage of FOSS licenses, and that courts and commentators should consider employing these principles in their interpretation of these documents.

\section{The Interpretation of Templates}

UV Industries was a publicly traded company that was engaged in heavy industry. During the period between 1965 and 1977, UV borrowed hundreds of millions of dollars in five separate lending transactions. ${ }^{7}$ The agreements documenting these transactions provided that, in the event that UV

source license, the "comments of license stewards are interesting but of questionable relevance"); Determann, supra note 2, at 1491 (asserting that the "examples, explanations, and programmatic and ideological statements" of the Free Software Foundation are likely to be of limited relevance if the FSF is not itself a party to the dispute).

Robert W. Gomulkiewicz, De-Bugging Open Source Software Licensing, 64 U. PITT. L. Rev. 75 n.185 (2002) (asserting that "once a hacker applies the license to his or her software, it is the hacker's intention that controls" interpretation of the license).

5 Rosen at 120 (asserting that "If there is an ambiguity or uncertainty of interpretation in a license, the license will generally be interpreted against the licensor regardless of what the license drafter meant to say"); id. at 282 (under general principles of contractual interpretation "courts may protect individual consumers from unfair license conditions where they wouldn't bother to protect a sophisticated company..."); Meeker at 100 (interpretation of the GPL may employ the canon of contra preferentum"); Determann at 1491. See also Gomulkiewicz n. 40 (noting that the ordinary canon that contracts should be interpreted against the drafter may, in the context of open source licensing, be modified somewhat by intellectual property law).

6 Similarly, it may sometimes be possible to characterize the often terse "fair, reasonable and non-discriminatory" (FRAND) patent licensing commitment in similar manner - as template language meant to evoke community expectations rather than negotiated terms to be construed as per the parties' expectations. Admittedly, the specific language used to implement FRAND obligations may not always be unmodified boilerplate. See, e.g., Jorge L. Contreras and Anne Layne-Farrar, Non-Discrimination and FRAND Commitments in CAMBridge HANDBook OF TECHNICAL Standardization Law: Competition, Antitrust, and Patents 186, 190 (Jorge L. Contreras, ed., 2017) (suggesting differences in the meaning of FRAND commitments that prohibit all "discrimination" as opposed to only "unfair discrimination"). But see Stephen J. Choi \& Mitu Gulati, Contract as Statute, 104 Mich. L. Rev. 1129, 1149 (asserting that under a boilerplate analysis "it is not at all clear that the small differences in language ... should be given much weight at all").

7 Sharon Steel Corp. v. Chase Manhattan Bank, N.A., 521 F. Supp. 104, 107 (S.D.N.Y. 1981), aff'd 691 F.2d 1039 (2d Cir. 1982), cert. denied.460 U.S. 1012 (1983). 
would merge or consolidate with another corporation, or in the event that UV would sell "all or substantially all" of its assets to another corporation, the successor company would be able assume UV's rights and obligations under these agreements. ${ }^{8}$ As many lawyers would immediately recognize, the statement that the lending agreements could be assumed by a purchaser of "all or substantially all" of UV's assets is transactional boilerplate - language reused repeatedly in transactions, but to which the parties often devote little thought and less negotiation.

Sharon Steel Corporation indeed eventually purchased "all or substantially all" of UV Industries in November 1979. ${ }^{9}$ But Sharon's purchase only occurred after UV Industries decided to liquidate, and after UV had already sold one of its most valuable businesses in March 1979 and another subsidiary in July $1979 .{ }^{10}$ As such, while UV and Sharon claimed that Sharon was entitled to assume UV's rights and obligations under the five lending transactions, other parties to those transactions disagreed. In essence, the high stakes litigation came down to the interpretation of the long-neglected boilerplate provision: when the contract referred to a purchase of "all or substantially all" of UV's assets, should those assets be measured as of the date of Sharon's purchase of those assets (in which case Sharon did indeed by definition purchase all of UV's assets) or the date that UV commenced its liquidation (in which case, Sharon had purchased only the dim remains of the disintegrating UV)? ${ }^{11}$

During the litigation, the parties presented evidence as to the meaning of the disputed clause in the contract. ${ }^{12}$ But, in the end, the court found that the "meaning of the language was simply not discussed" during the negotiations of the documents. ${ }^{13}$ "Rather," the court stated, the clauses "were boilerplate provisions universally included" in contracts of that type. ${ }^{14}$ As such, there was no actual evidence as to the parties intentions regarding the meaning of these clauses. The court eventually decided the matter not by searching for the intentions of the parties but rather based on an examination of the interests that the court saw those clauses as protecting, both within the specific transaction at issue in the case, but also in the multitude of other transactions in which such boilerplate clauses were used.

This approach was sustained on appeal. ${ }^{15}$ According to the court of appeals, "boilerplate provisions are ... not the consequence of the relationship of particular borrowers and lenders and do not depend on the particularized intentions of the parties." ${ }^{16}$ As such, according to the court, the meaning of those clauses should not be determined by examining the facts specific to any specific transaction (such as the intentions of the parties in any particular transaction) but must instead be found in market understandings of the standardized contract at issue. Such market understandings could be inferred by looking to the commentary of industry bodies on the relevant boilerplate provisions. ${ }^{17}$ In addition, such market understandings could be abstracted by the courts through an analysis of the fundamental interests of the parties in the category of transaction before the court, without examination of the intentions or goals of the parties in any specific matter. ${ }^{18}$

This approach, according to the court of appeals, had the advantage of ensuring "uniformity of interpretation. ${ }^{19}$ Were the interpretation of such clauses dependent on the specific intentions of the parties in any individual transaction, such boilerplate could take on a different meaning in each

$8 \quad I d$.

9 Id. at 109

10 Id. at $108-109$

11 Id. at $112-13$.

12 Id. at 113.

13 Id.

14 Id.

15 Sharon Steel Corp. v. Chase Manhattan Bank, N.A., 691 F.2d 1039 (2d Cir. 1982).

16 Id. at 1048 .

17 Id. at $1048-50$

$18 I d$. at 1051 (holding that the interpretation of the clauses at issue should "best accommodate[] the principal interests of corporate borrowers and their lenders"). See also Choi \& Gulati, supra note 6 at 1156 (noting that the court in Sharon Steel recognized the "need to defer to market understandings" in interpreting boilerplate contracts). 19 Id. 1048 
litigation. Such uncertainty of interpretation could "greatly impair the efficient working of capital markets." ${ }^{20}$ Allowing such ambiguities in the meaning of boilerplate provisions would "vastly increase the risks and, therefore, the costs of borrowing with no offsetting benefits either in the capital market or in the administration of justice." 21

The interpretive approach of Sharon Steel has been followed by other courts. For example, other United States courts of appeals have used the Sharon Steel doctrine in construing standard form provisions in a mortgage loan agreement. ${ }^{22}$ In these latter cases, the Sharon Steel principles were reinforced by the fact that the provisions at issue were mandated by federal housing law. In other words, the relevant provisions were required by the legislature, and "individual contracting parties neither drafted the standard-form language nor had the authority to alter or omit that language through negotiation." ${ }^{23}$ As such, the court held that "interpretation of the provision cannot vary from place to place or from contract to contract." 24

\section{From Indentures to Open Source}

The typical FOSS license describes a very different transaction than a complex debt agreement. Nonetheless, despite these differences, the Sharon Steel principles applicable to interpretation of the latter can be usefully applied to the former. As with the boilerplate provisions in financial contracts, FOSS licenses are almost always used as template agreements, and rarely are the terms of any specific FOSS licensing transaction subject to any amount of negotiation. Indeed, FOSS licensing transactions would seem to depend on transactional templates to a larger extent than the financial contracts at issue in Sharon Steel. First, FOSS licenses are often applied simply by reference to the applicable licensing template, without detailing the specific legal language of the template license. Second, FOSS licenses are applied as templates throughout a wide range of transactional relationships. For example, FOSS licenses can be applied at multiple points in a supply chain such as between the original developer and an open source project, between the open source project and a distributor of the software, and between any of the foregoing to the end user of the software. Moreover, template FOSS licenses are often used to describe licensing transactions both between large and legally sophisticated technology companies and also with legally unsophisticated individuals. The language of FOSS licenses remains constant despite this heterogeneity of transactional categories and transacting parties.

Moreover, as the Sharon Steel court noted with respect to financial contracts, the uniformity of FOSS licenses serves important goals in the FOSS ecosystem. Open source concerns for uniformity are strongly reflected in community discussions regarding "license proliferation", in which some community participants have noted with apprehension the growing diversity of FOSS licensing terms. ${ }^{25}$ According to these concerns, the increasing variety of licensing terms complicates the choice of appropriate FOSS license for any particular project and, when projects include a multiplicity of licenses, obscures the legal terms that are applicable to the project as a whole. ${ }^{26}$ Fundamentally, these concerns about license proliferation reflect a desire to limit FOSS licenses to a well-defined menu of license templates, and emphasize the need for standardization in FOSS licensing. ${ }^{27}$ Second, any search for any "meeting of the minds" between the parties to a FOSS license may simply not be practical. FOSS projects can include numerous contributions from thousands of individual and

$20 I d$.

21 Id.

22 Kolbe v. BAC Home Loans Servicing, LP, 738 F.3d 432 ( $1^{\text {st }}$ Cir. 2013); Feaz v. Wells Fargo Bank, N.A., 745 F.3d 1098 (11 Cir. 2014).

23 Id.at 1105.

24 Id.

25 See, e.g., Open Source initiative, Report of License Proliferation Committee and Draft FAQ.

$26 I d$.

27 See Rosen, supra note 2, at 235 (stating that open source "licensors should use an existing template license. Please don't invent your own. The open source community is not seeking new licenses to analyze and interpret"). 
corporate developers. Depending on the structure of the specific project, end users may receive a grant of a FOSS license from each developer in this crowd, and each of those developers may have slightly different licensing intentions. ${ }^{28}$ As such, without a requirement of uniform interpretation, attempts to excavate the intentions of FOSS participants may crash against the multitude of different understandings held by each copyright holder in a project. Third, from a theoretical viewpoint, the importance of uniformity of open source interpretation is underscored by the emphasis of FOSS communities on the principle of "non-discrimination". ${ }^{29}$ Both the Open Source Initiative and the Free Software Foundation have seen "non-discrimination" as a cardinal tenet of FOSS licensing. ${ }^{30}$ However, this principle could be violated if courts were to construe FOSS licenses differently for various participants in the FOSS community. As such, the principle of "non-discrimination" points towards the importance of uniformity in the interpretation of Free and Open Source Software licenses.

These arguments for the uniform interpretation of FOSS licenses are buttressed by the fact that open source licensors may in many copyleft circumstances have little power to vary the terms of their licenses. For example, a developer contributing code to a project licensed under the GPLv3 may own the copyright in her individual contribution. However, those privileges of ownership would not include the right to change the license applicable to the developer's specific code contribution - the GPLv3 license applicable to the project as a whole would also likely mandate that any additional code contributed to the project also be licensed under the same GPLv3 language. ${ }^{31}$ These circumstances recall the cases discussed above in which courts refused to countenance different interpretations of contract provisions mandated by federal law. ${ }^{32}$ As with those cases, many situations in FOSS licensing may demand a uniformity of licensing interpretation, given that the copyright holder is compelled to use specific licenses provisions that she did not choose and that she does not have the power to change.

\section{Consequences}

This Section briefly outlines some of the possible ramifications of adopting a "boilerplate" theory of interpretation in the context of FOSS licenses.

\section{The Rising Importance of Industry Organizations}

Several courts that followed the lead of Sharon Steel have emphasized how the interpretations put forth by industry associations provide insight into the market understanding of boilerplate provisions. Indeed, the Sharon Steel court itself pointed to the Commentaries on Indentures published by the American Bar Association. ${ }^{33}$ Similarly, other courts following Sharon Steel have asserted that, in the context of standardized contracts, "stability and uniformity of interpretation" can be enhanced "by looking to the multi-decade efforts of leading practitioners to develop model indenture provisions." ${ }^{34}$ Such model provisions and associated commentaries "can provide powerful evidence of the established commercial expectations of practitioners and market participants." ${ }^{35}$ Such interpretative methods have also been employed by courts looking at other categories of standardized agreements. In re Lehman Bros. Holdings., Inc. v. Intel Corp. concerned the interpretation of the Master

28 For a summary (and criticism) of the standard view concerning the ownership and licensing of FOSS projects, see Pamela S. Chestek, A Theory of Joint Authorship for Free and Open Source Software Projects, 16 CoLo. TECH L.J. 285 (2018)

29 See generally, Eli Greenbaum, The Non-Discrimination Principle in Open Source Licensing, 37 Cardozo L. Rev. 1297 (2015)

30 Id. at 1302

31 See Section 5(c) of the General Public License version 3 (requiring that works "based on the Program, or the modifications to produce it from the Program" may be conveyed only "as a whole, under this License").

32 See supra text accompanying notes $22-24$

33 691 F.2d at 1049

34 Concord Real Estate CDO 2006-1 v. Bank of Am. N.A., 996 A.2d 324, 331 (De. Ch. 2010)

35 Id. 
Agreement of the International Swaps and Derivatives Association (ISDA). ${ }^{36}$ ISDA provides template agreements for entering into complex financial swaps transactions, and the dispute in this case concerned the interpretation of one of the boilerplate provisions in the standard agreement. The details of the specific dispute are beyond the scope of this article. Significantly, however, in resolving the dispute over the boilerplate provisions, the court looked extensively to the ISDA User Guide, which provided the ISDA understanding of how the template agreements should be interpreted.$^{37}$ In addition, the court accepted testimony from one of the drafters of the ISDA agreements and received a legal brief from the ISDA. ${ }^{38}$ Generally, the court found that this interpretive approach gave effect to the "clarity, certainty, and predictability" sought by parties entering into a standard form ISDA agreement. ${ }^{39}$

FOSS organizations, especially those that have drafted licenses, have often put forward interpretations of licenses in common use. Most prominent perhaps is the list of Frequently Asked Questions (FAQ) published by the Free Software Foundation (FSF) to interpret the GPL license drafted by the FSF. ${ }^{40}$ That FAQ document puts forward understandings of the not-always-crystalclear language of the GPL. In addition, the Free Software Foundation has made available extensive documentation concerning the drafting process of GPLv3, which can provide insight into the meaning and goals of the sometimes complex language of the license. ${ }^{41}$ Similar documentation has been put together by other organizations regarding other FOSS licenses advanced by those bodies. ${ }^{42}$ While some commentators have asserted that these documents should have a negligible place in the interpretation of FOSS licenses, the Sharon Steel line of case suggests otherwise. Instead, courts following the Sharon Steel method of interpretation could find that such documents provide evidence of "commercial expectations" of participants in the FOSS community and should be admitted as evidence in interpreting any ambiguous provisions in FOSS licenses. ${ }^{43}$ Such courts could also decide that giving weight to the interpretations of such industry bodies would advance consistency and stability in the interpretation of the template license documents. ${ }^{44}$

Of course, the interpretations of industry groups only reveal "community expectations" when those groups actually represent a broad range of the interests in the community. To the extent a FOSS organization could be seen as representing only a limited slice of the community, or to the extent such organization was generally viewed as having adopted non-consensus views regarding the template, then a court may consequently accord less weight to the interpretations of that body. ${ }^{45}$

362015 Bankr. LEXIS 3991 (S.D.N.Y.)

37 Id. at $* 36$

38 Id. at *40. But see Great Minds v. Fedex Office \& Print Servs., 2017 U.S. Dist. LEXIS 24063 (E.D.N.Y.) (not allowing the Creative Commons Corporation to file an amicus brief, since the court was not then required to interpret the license text).

39 Id. at $* 42$.

40 GNU Operating System, Frequently Asked Questions about the GNU Licenses, https://www.gnu.org/licenses/gplfaq.en.html.

41 This documentation is available at Free Software Foundation, Welcome to GPLv3, http://gplv3.fsf.org/. For commentators advocating use of such material in interpreting boilerplate, see Choi \& Gulati, supra note 6 at 1167-68 (asserting that courts should look to the historical record of the drafting process).

42 See, e.g., Apache Software Foundation, Frequent Questions about Apache Licensing, http://www.apache.org/foundation/license-faq.html; Mozilla, MPL 2.0 FAQ, https://www.mozilla.org/en-US/MPL/2.0/FAQ/.

43 Indeed, courts may also find interpretive support in statements from such institutions regarding the historical background of FOSS licenses. For an example of a commentator attempting to use such evidence in the interpretation of FOSS licenses, see David J. Kappos \& Miling Y. Harrington, The Truth about OSS-FRAND: By All Indications, Compatible Models in Standards Settings, 20 ColumB. SCI. \& TECH L.R. 242, 247 (2019) (using recollections of current staff at MIT and University of California, Berkeley to interpret the MIT and BSD licenses, respectively). For commentators advocating such an approach in general, see Choi \& Gulati, supra note 6 at 1167 (asserting that the "starting point" in the analysis of boilerplate terms should be the "historical understanding" of the clause, including "discerning the intent of the original drafters").

44 Courts construing FRAND licensing commitments have also looked towards the understandings and goals of standards organizations in interpreting that commitment. For example, in FTC v. Qualcomm, 2018 U.S. Dist. LEXIS 190051, *3839 (N.D. Cal.), the court made use of the guidelines and "statements of purpose" of the relevant standard-setting organization in interpreting the FRANC commitment, even though the court framed this inquiry as a search for the intent of the contracting parties. Id. at $* 26$.

45 See, e.g., Gregory Klass, Boilerplate and Party Intent, 82 Law and Contemporary Problems 105, 127 (2019) (noting, in 


\section{The Decline of Individual Intentions}

FOSS licensors may occasionally pepper template FOSS licenses with their own understandings of the applicable license. Such glosses could either relax or reinforce the obligations under the license for example, a licensor could provide a lax interpretation of license obligations or alternatively could describe a strict enforcement policy that goes beyond ordinary community understandings of the license. These glosses provide insight into how the licensor itself understands the parties' obligations under the license, even if those intentions may not always be consistent with community understandings of the license text. The FAQ document made available by the FSF can be seen a prominent example of an interpretive gloss - even if the FAQs are not construed as providing an objective interpretation of the license text itself, they are certainly evidence of the specific licensing intentions of the FSF when acting as a copyright holder.

A classical approach to FOSS licenses could view these glosses as integral to the process of interpreting the license terms - after all, in such circumstances the licensor has made its intentions clear, and a licensor can generally choose the terms under which its software is made available. ${ }^{46}$ On the other hand, a "boilerplate" approach to interpretation could result in a court disregarding evidence of a specific licensor's intentions in favor of a more standardized, consistent approach to interpreting template language. For example, in Kolbe v. BAC Home Loans Servicing, the appellate opinion precluded the parties from presenting evidence about their contractual intentions regarding a provision in a mortgage contract. ${ }^{47}$ One of the appellate judges asserted that evidence about "the parties' unique intentions regarding a uniform clause is generally uninformative because, unlike individually tailored contracts, uniform clauses do not derive from the negotiations of the specific parties to a contract." ${ }^{48}$ As such, courts following Sharon Steel may feel comfortable in setting aside evidence of the parties' intentions in a FOSS licensing transaction.

Of course, some glosses could become so well-accepted that they would become evidence of custom or usage. Sharon Steel itself noted that such evidence of custom or usage could affect the interpretation of boilerplate provisions, presumably because such evidence would point to industrywide interpretations and not result in inconsistencies of interpretation of the same template contract. $^{49}$

\section{Canons of Interpretation}

Some commentators have asserted that courts should resort to common rules of contract interpretation when resolving ambiguities in FOSS licenses. For example, courts could employ the interpretative canon of contra proferentem, which provides that an ambiguous contract will be construed against the party that drafted the contract. According to this canon, it is the drafter of the contract that had the best opportunity to clarify and sharpen its language, and so that drafter should

observing courts' contrasting approaches to the view of the Insurance Services Office and the ISDA, that “[t]he ISO's partisan nature distinguishes it from the ISDA, which generally represents the interests of both sides in a derivatives sale. Consequently, whereas it can be appropriate for courts to look to the ISDA Master Agreement's drafting history and to the ISDA's present position on its meaning, it would be inappropriate to give similar weight to the drafting history of ISO standard forms or to ISO's present understanding of them").

46 A licensor may not have unbridled freedom to annotate a FOSS license. For example, section 7 of GPLv3 allows licensees to ignore any "further restrictions" that the licensor may impose in addition to the license terms. It is unclear how a court would approach a situation in which a licensor added a "further restriction"- would a court indeed allow the licensee to simply "remove" that further restriction as permitted by the original text of GPLv3, or would a court find a way to reconcile the contradictory texts? A situation more relevant to the topic of this article, and perhaps subject to even more legal haziness, would be a situation where a licensor publishes a restrictive interpretation of the GPL, and a licensee counters that such restrictive interpretation should be viewed as a severable "further restriction".

47738 F.3d 432 ( $1^{\text {st }}$ Cir. 2013).

48 Id. at 436. See also Kaiser Aluminum Corp. v. Matheson 681 A.2d 392 (Del. 1996). In Kasier, the Supreme Court of Delaware was called on to interpret the "hopelessly ambiguous" language of a corporate certificate of incorporation. Despite the opacity of the contract, the court noted that it was reluctant "to rely on extrinsic evidence" of the parties' intentions, since that could introduce "inconsistencies" in the interpretation of such template documents. Id. at 398

49 Sharon, at 1048. 
bear the risk when contract language does not provide a clear meaning. ${ }^{50}$ In the context of FOSS licenses, applying this canon would mean, for example, that in a copyright infringement suit brought by the FSF (as a copyright holder) regarding non-compliance with the GPL, a court may construe the ambiguities of the GPL against the FSF. ${ }^{51}$ Since the FSF acts as the drafter and license steward of the GPL, a court may hold that it should be the risk of ambiguities in the license. ${ }^{52}$

However, some courts have suggested that the interpretive rule of contra proferentem cannot be "readily applied" in the context of template agreements. ${ }^{53}$ According to this approach, the use of this interpretative principle should be avoided in circumstances in which its application would result in the inconsistent interpretations of boilerplate language. ${ }^{54}$ Applying the canon of contra proferentem in the context of FOSS license would certainly implicate this concern - for example, the GPL could be interpreted in a certain way if the FSF were the copyright holder bringing suit for infringement of the license, but would be interpreted in a different manner were the suit to be brought by another party. In effect, application of the canon of contra proferentem would result in a license that functions differently depending on the identity of the licensor. These differences of interpretation would undermine the stable and consistent interpretation of FOSS licenses. ${ }^{55}$ Moreover, allowing the meaning of a FOSS license to mutate according to the identity of the parties to the license would violate the bedrock FOSS principle of non-discrimination. While parties could apply the same formal license text, the interpretation of that text would differ depending on the parties to the licensing transaction.

\section{Conclusion}

The classical model of contractual interpretation involves a search for the intent of the contracting parties. But the boilerplate nature of FOSS licenses distinguishes them from the classical model of contracts. In a standard FOSS licensing transaction, the parties may have little regard for the linguistic details of the license, and an excavation of the fossil record of the parties' intentions with regard to the specific language of the license may raise little of substance. This short article has shown that in courts in other contexts have often recognized the unique interpretative challenges posed by such boilerplate language, and suggested that courts may employ such interpretive techniques in the context of FOSS licensing as well.

50 See, e.g., Intel Corp. v. VIA Technologies, Inc., 319 F.3d 1357, 1363 (Fed. Cir. 2003) (applying contra proferentem in the interpretation of Intel's template royalty-free license agreements for patents applicable to a technological standard, because "Intel alone drafted the agreement and had complete control over the language of its terms"). While this case involved a template license, the usage of the template at issue differed from FOSS licenses in that the template was only used by a specific licensor (Intel) in the licensing of patents for a specific standard.

51 For some commentators suggesting the application of contra proferentem in FOSS licenses, see supra note 5.

52 To some extent, seeing the FSF as the sole "drafter" of GPLv3 is not completely accurate. Rather, the GPLv3 license was drafted in a public process which included many participants. Though the FSF seems to have had sole control over the final license text, the concerns animating the intermediate and final drafts of the license text were made publicly available. See generally, Free Software Foundation and Software Freedom Law Center, GPL3 Process Definition (2006), at http://gplv3.fsf.org/gpl3-process.pdf. The author has not found court cases that address the application of contra proferentem in such situations.

53 Broad v. Rockwell Int'l Corp., 642 F.2d 929, 947 n.20 (5 $5^{\text {th }}$ Cir. 1981)

54 nother concern raised by courts discussing the application of contra proferentem in template documents is that the language of contractual boilerplate was not "actually discussed and thought about by the parties." Id. In other words, in a transaction in which the parties simply applied boilerplate, neither party actually negotiated the language of the agreement and so there is no "drafter" against which ambiguities can be interpreted. As noted above, FOSS licenses may actually suffer from the opposite concern - while FOSS licenses typically have a license "steward" that publishes the license, FOSS licenses have also been drafted in a public process in which a surfeit of participants are able to submit comments and concerns regarding the license language. See supra note 52.

55 See also David Horton, Flipping the Script: Contra Proferentem and Standard Form Contracts, 80 U. Colo. L. Rev. 431 , 436 (2009) (arguing that without the rule of contra proferentem, the meaning of mass-produced terms would fluctuate with the particulars of each deal, leading to perverse results"). 


\section{About the author}

Eli Greenbaum is a partner in the Jerusalem office of Yigal Arnon \& Co and adjunct faculty at the Interdisciplinary Center at Herziliya 


\section{Licence and Attribution}

This paper was published in the Journal of Open Law, Technology, \& Society, Volume 12, Issue 1 (2021). It originally appeared online at http://www.jolts.world

This article should be cited as follows:

Greenbaum, Eli (2021) 'Open Source Interpretation', Journal of Open Law,

Technology, \& Society, 12(1), pp $1-10$

DOI: $10.5033 /$ jolts.v12i1.143

Copyright (C) 2021 Eli Greenbaum

This article is licensed under a Creative Commons Attribution 4.0 CC-BY available at

https://creativecommons.org/licenses/by/4.0/

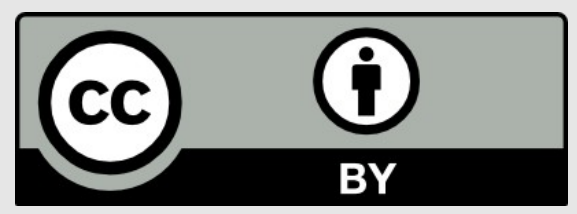

